\title{
REVIEW
}

\section{Cirrhotic cardiomyopathy: a pathophysiological review of circulatory dysfunction in liver disease}

\author{
S Møller, J H Henriksen
}

Heart 2002;87:9-15

The systemic circulation in patients with cirrhosis is hyperdynamic with an increased cardiac output and heart rate and a reduced systemic vascular resistance as the most pronounced alterations. The concomitant cardiac dysfunction has recently been termed "cirrhotic cardiomyopathy", which is an entity different from that seen in alcoholic heart muscle disease. Clinically, these patients present with sodium fluid retention and strain often unmasks the presence of latent heart failure. No specific treatment can yet be recommended but caution should be used with respect to procedures that may stress the heart such as shunt implantation and liver transplantation.

See end of article for authors' affiliations

Correspondence to: Dr S Møller, Department of Clinical Physiology, 239, Hvidovre Hospital, DK-2650 Hvidovre,

Denmark;

soeren.moeller@hh.hosp.dk

Accepted

12 September 2001
$\mathrm{P}$ ast decades have seen the appearance of new techniques for the study of different aspects of cardiac function. Our knowledge of cardiovascular pathophysiology has improved considerably, including our understanding of cardiovascular complications of liver disease. Kowalski et al ${ }^{1}$ were the first to report that patients with cirrhosis had abnormal cardiovascular function and a prolonged QT interval. The systemic circulation in patients with decompensated cirrhosis is hyperdynamic and characterised by increased heart rate and cardiac output ( $\mathrm{CO}$ ) and decreased systemic vascular resistance with low normal or decreased arterial blood pressure. ${ }^{2-4}$ Among the factors that may increase the $\mathrm{CO}$ in patients with cirrhosis are increased sympathetic nervous activity, increased blood volume (increased preload), and the presence of arteriovenous communications. ${ }^{5-7}$ Many of the patients present with dyspnoea, fluid retention, and limited exercise capacity. ${ }^{4} 9$

The use of new investigative modalities has shown several lines of evidence of impaired cardiac contractility and performance in patients with cirrhosis and has led to the introduction of the new clinical entity, cirrhotic cardiomyopathy. This term implies a condition with defective myocardial contractility under physical and pharmacological strain, although the entity has not yet been finally classified and the mechanisms behind the cardiac abnormalities are only partly understood. ${ }^{10}$ The objective of this review is to summarise pathophysiological and clinical evidence of cardiac dysfunction in cirrhosis.

\section{THE CIRRHOTIC HEART}

Heart mass and volumes

In most studies of patients with cirrhosis, the heart mass has been found to be within the nor- mal range. ${ }^{11} 12$ However, some have reported an increased left ventricular mass ${ }^{13}{ }^{14}$ and in a recent experimental study of portal hypertensive rats, left eccentric hypertrophy was found to correlate directly with the degree of hyperdynamic circulation. ${ }^{15}$ The determination of heart volumes in patients with cirrhosis has given somewhat different results depending on the methods used. ${ }^{16-18}$ In echocardiographic studies, Kelbæk et $a l^{19}$ and Rector et $a l^{17}$ found the size of the left ventricle to be normal and that of the left atrium enlarged..$^{21}$ Others, however, have reported increases in both the end diastolic and the end systolic volumes of the left ventricle. ${ }^{1322-25}$ Wong et $a l^{16}$ used radionuclide angiography and they reported normal left ventricular systolic and diastolic volumes, including the stroke volume. Normal and increased right ventricular and atrial volumes have been found by echocardiography. ${ }^{17} 20212627$ In contrast, magnetic resonance imaging has shown reduced right ventricular and atrial dimensions and slightly increased left ventricular and atrial volumes. ${ }^{12}$ Reduced right heart volumes could reflect a general contraction of the central blood compartment in patients with cirrhosis, as previously suggested by other techniques. ${ }^{28}$ The change in the left ventricular dimensions in cirrhosis is related to haemodynamic dysfunction. Thus, Lewis et al ${ }^{29}$ found significant correlations between the left ventricular end diastolic diameters on one hand and $\mathrm{CO}$, stroke volume, mean arterial blood pressure, and blood volume on the other. Moreover, significant direct correlations between plasma atrial natriuretic peptide and left atrial volume and left ventricular end diastolic diameter have been reported. ${ }^{20} 21$

In conclusion, the size of the left atrium and ventricle in patients with cirrhosis is normal to increased. No definite conclusion can be offered as to the size of the right heart.

\section{Heart pressures}

Most published studies show the right ventricular pressure, pulmonary artery pressure (PAP), and left atrial or pulmonary capillary wedge pressure (PCWP) to be at the upper normal limit but within the normal range during rest (table 1); the severity of the liver disease per se does not seem to affect cardiac pressures. ${ }^{30-32}$ However, fluid retention with formation of ascites and haemodynamic

Abbreviations: $\mathrm{CO}$, cardiac output; PAP, pulmonary artery pressure; PCWP, pulmonary capillary wedge pressure; RAP, right atrial pressure; TIPS, transvenous intrahepatic portosystemic shunt 
Table 1 Haemodynamic changes in different vascular territories in patients with cirrhosis at rest

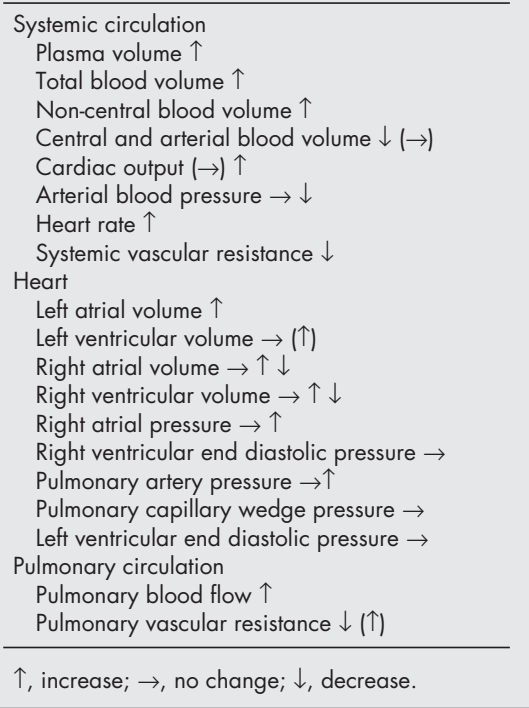

disturbances with increased blood volume may result in increased right atrial pressure (RAP), ${ }^{30}$ and paracentesis with removal of ascitic fluid has been shown to lower the RAP, PAP, and PCWP. ${ }^{33}$ Physical exercise, pharmacological stress, and therapeutic procedures may affect cardiac pressures. Thus, the left ventricular end diastolic pressure increases but the cardiac stroke index and left ventricular ejection fraction fall during exercise, which indicates an abnormal ventricular response to an increase in ventricular filling pressure. ${ }^{193134}$ Reduced left ventricular afterload (reduced systemic vascular resistance, low arterial blood pressure, and increased arterial compliance) may mask left ventricular failure. ${ }^{14}{ }^{19}{ }^{35-37}$ By infusion of angiotensin, Limas et $a l^{38}$ increased the systemic vascular resistance by $30 \%$ and found that the PCWP, which reflects left ventricular end diastolic volume, increased twice with no change in CO. A failure to increase CO despite an increased ventricular filling pressure indicates that normalisation of the afterload impairs cardiac performance and unmasks left ventricular failure. $^{38}$ Interestingly, this effect on the PCWP was not improved after addition of digoxin. Similar results, with increases in the RAP, PAP, right ventricular pressure, and PCWP, have been achieved by normalising the arterial blood pressure with infusion of terlipressin and octreotide. ${ }^{39-41}$ Infusion of a plasma protein solution increased CO, as well as RAP, PAP, and PCWP, whereas infusion of packed red blood cells did not change these variables. ${ }^{42}$ In a recent study by Forrest et $a l,{ }^{43}$ oral administration of the adenosine antagonist theophylline significantly decreased PAP and PCWP, thus suggesting that adenosine could be implicated in the cardiovascular dysfunction present in cirrhosis. Surprisingly, lowering the afterload by infusion of the nitric oxide donor L-arginine in cirrhotic patients produced significantly increased RAP, PAP, and PCWP, despite a decreased arterial blood pressure. ${ }^{44}$ However, it is possible that this is a direct effect of nitric oxide on myocardial contractility.

Transvenous intrahepatic portosystemic shunt (TIPS) is frequently used in the treatment of bleeding oesophageal varices and refractory ascites. ${ }^{45}$ Insertion of a TIPS results in an immediate increase in the ventricular preload because a high splanchnic blood flow is delivered into the systemic circulation. Several studies have noted an aggravation of the hyperdynamic circulation with increased CO, RAP, PAP, and PCWP immediately after TIPS placement. ${ }^{46-48}$ However, cardiac pressures and CO tend to become normal two or three months after this therapeutic procedure and some authors report no or only transient changes in cardiac pressures after TIPS insertion. ${ }^{40}{ }^{50}$ In the past, a peritoneovenous shunt for treatment of refractory ascites was frequently implanted. This procedure, which further increased CO, was in a considerable number of patients complicated by the development of pulmonary oedema indicating a latent cardiac inability unmasked by the increased preload. ${ }^{51}$ At present, it is not possible to predict which patients will develop cardiac complications such as high output congestive heart failure after implantation of TIPS and peritoneovenous shunts, and the procedures should be considered with caution in patients with limited cardiac reserve. ${ }^{46} 48$

Most patients with cirrhosis have almost normal cardiac pressures when resting supine. These pressures become abnormally raised by procedures stressing the heart, such as pharmacological vasoconstriction, exercise, and the increased portosystemic shunting resulting from insertion of a TIPS. This should be considered when applying these procedures in patients with limited cardiac reserve, but at present no specific guidelines for the identification of patients at risk can be given.

\section{LEFT VENTRICULAR DYSFUNCTION Systolic dysfunction}

The circulation of the patient with cirrhosis is hyperdynamic, with increased CO and heart rate, expanded plasma volume, and low arterial blood pressure and systemic vascular resistance. ${ }^{52}$ The pathophysiological background of the increased CO is under discussion and a key feature is the size of the central and arterial blood volume. ${ }^{16} 205354$ Reduced central and arterial blood volume would lead to deactivation of arterial baroreceptors, increased sympathetic nervous activity and, thereby, increased heart rate and $\mathrm{CO}^{52}$ However, the circulation seems to be hyperdynamic only in the supine position, normalising after tilting. ${ }^{556}$ Results of studies with postural changes suggest that an increased preload contributes to the increased CO in the supine position. Interestingly, in patients with compensated cirrhosis and arterial hypertension there is no evidence of a hyperdynamic circulation. ${ }^{57}$ In addition, Laffi et $a^{25}$ recently described reduced left ventricular end diastolic volume and reduced ejection fraction after standing, which indicate an impaired myocardial response to an erect posture. Studies of patients with cirrhosis found after head out water immersion an increase in $\mathrm{CO}$ and central and arterial blood volume, which also support an altered distribution of the plasma volume as a cause of the hyperdynamic circulation. ${ }^{58}$ Left ventricular ejection fraction has been reported to be normal at rest in some studies. ${ }^{13} 193459$ After exercise, the left ventricular ejection fraction increases significantly less in patients with cirrhosis than in matched controls. ${ }^{1934}$ Aerobic exercise capacity and maximal heart rate are lower in most patients with cirrhosis. ${ }^{193459}$ The reduced cardiac performance is probably caused by a combination of blunted heart rate response to exercise, reduced myocardial contractility, and profound wasting of skeletal muscle with impaired extraction of and demand for peripheral oxygen. ${ }^{8960}$

After liver transplantation, CO decreases and arterial blood pressure and the systemic vascular resistance increase. ${ }^{32} 6162$ These changes may be attributed primarily to normalisation of the liver function whereas specific treatments with, for example, cyclosporin also may play a part. Liver transplantation is associated with a high incidence of cardiovascular complications, which is an important cause of mortality after transplantation. ${ }^{63}$ Identification of patients at risk of developing cardiac failure in the post-transplantation period has been attempted by dobutamine stress echocardiography ${ }^{64}$ However, in this study of 190 patients, no preoperative echocardiographic parameters, including ischaemia on dobutamine echocardiography, predicted these perioperative events. ${ }^{64}$ 


\section{Diastolic dysfunction}

Patchy fibrosis and increased heart weight may affect the stiffness of the myocardial wall and result in impaired left ventricular filling and diastolic dysfunction. ${ }^{10}$ Expanded blood volume may increase the cardiac preload, thus contributing to the persistent increase in CO, with overloading and impaired cardiac contractility as the outcome. ${ }^{123556}$ Studies in which dextran was infused in human and experimental cirrhosis showed a limited cardiac preload reserve with a decreased ability to modulate cardiac performance under various loading conditions. ${ }^{11}{ }^{65}$ Recent studies of ventricular diastolic filling in cirrhosis support the presence of a subclinical myocardial disease with diastolic dysfunction with a decreased E:A ratio, which in patients with ascites improves after paracentesis. ${ }^{14262766}$

Patients with cirrhosis may have an increased, normal, or even reduced preload and a reduced afterload. Latent systolic and a diastolic dysfunction with reduced work capacity is present and becomes in some patients manifest if the heart is challenged. The type of cardiac insufficiency in cirrhosis may best be characterised as a high CO failure. It is likely that the reduced systolic cardiac dysfunction in cirrhosis contributes to the general low degree of physical activity reported in several studies. $^{367}$ Thus, after liver transplantation, both physical activity and cardiac function seem to improve ${ }^{67}$ Diastolic dysfunction may be a significant factor in the development of heart failure, may precede systolic dysfunction in patients with cirrhosis, and may play a part in the pathogenesis of sodium fluid retention in cirrhosis. ${ }^{1466}$

\section{Conductance abnormalities}

The fluidity of the plasma membrane and the function of its ion channels have been shown to be impaired in cirrhosis. ${ }^{68}$ Thus, Moreau et al ${ }^{69}{ }^{70}$ have shown an altered control of vascular tone by $\mathrm{K}^{+}$and $\mathrm{Ca}^{++}$channels in various cells in experimental and human cirrhosis. A result of these changes, if they are generally present, could be electrophysiological abnormalities in cardiac excitation. Thus, Ward et $a l^{71}$ have recently shown a decrease in $\mathrm{K}^{+}$currents in ventricular myocytes from cirrhotic rats, which would tend to prolong the QT interval. A prolonged QT interval has previously been described in patients with liver disease, leading to ventricular arrhythmias and sudden cardiac death. ${ }^{172}$ Recently, Bernardi et $a l^{73}$ described a prolonged QT interval in patients with cirrhosis, which was significantly related to the severity of the liver disease, plasma noradrenaline (norepinephrine), and survival. Changes in the QT interval seem to revert with improved liver function, for instance, after liver transplantation. ${ }^{74}$ Results from a preliminary study from our group have indicated that the frequency adjusted QT is partly normalised in patients with cirrhosis after oral $\beta$ blocker administration. Whether this may be a beneficial effect of $\beta$ adrenergic blockade in addition to the effects on risk of bleeding from oesophageal varices remains to be validated. The prolonged QT interval in cirrhosis should most likely be considered an element in the cirrhotic cardiomyopathy and may be of potential use in identifying patients at risk. Future pathophysiological and clinical research is needed to assess the prognostic and therapeutic significance.

\section{EXTRACARDIAC FACTORS}

\section{Autonomic dysfunction}

Haemodynamic alterations may per se affect the function of the heart and reduced performance of the heart in cirrhosis may, on the other hand, contribute to low arterial blood pressure and the activation of vasoactive systems analogous to congestive heart failure. ${ }^{75}{ }^{76}$ Cardiovascular reflex tests of various studies have shown sympathetic and parasympathetic autonomic dysfunction in patients with cirrhosis depending on the severity of the disease. ${ }^{77-79}$ The location of the autonomic dysfunction is unknown but could be within the central nervous system because of damage to the peripheral nerves or because of changes in hormonal neurotransmission ${ }^{80}{ }^{81}$ (fig l).

Patients with cirrhosis exhibit enhanced activity of the sympathetic nervous system with increased burst frequency and increased circulating catecholamines in direct relation to the severity of the disease. ${ }^{5}$ The major triggers of the sympathetic overactivity seem to be baroreceptor mediated stimulation, owing to the low arterial blood pressure and hepatic dysfunction, and a volume receptor mediated stimulation, owing to reduced central and arterial blood volume. ${ }^{52}$ The sympathetic response to dynamic exercise seems to be normal in patients with cirrhosis, but the response to isometric exercise is clearly impaired. ${ }^{84}{ }^{30} 83$ Similarly, blood pressure responses to orthostasis are impaired, probably because of a blunted baroreflex function..$^{25-86}$ The haemodynamic effects of posture have been studied in detail by Bernardi et al, 555687 who have reported reversal of the hyperdynamic circulation after standing, but unaltered heart rate and arterial blood pressure, and increased circulating noradrenaline and increased renin activity. The blood pressure after active tilting is largely unchanged or even increased, and the prevalence of orthostatic hypotension in cirrhosis may not be significantly different from that in the normal population. ${ }^{79} 88$ In addition, abnormal cardiovascular responses to pharmacological stimulation with angiotensin II, noradrenaline, and vasopressin in terms of impaired responses in the blood flow and blood pressure have been reported. ${ }^{89-91}$

Enhanced sympathetic tone with increased cellular exposure to noradrenaline for longer periods is known to cause myocardial injury and impaired $\beta$ adrenergic function. ${ }^{76}$ Increased cardiac troponin I in patients with cirrhosis indicates that cardiac injury occurs in some patients. ${ }^{92}$ The pressor response to noradrenaline and other potent pressor substances, such as angiotensin II and vasopressin, is blunted in patients with cirrhosis. ${ }^{89} 93-96$ The decreased responsiveness could be a result of defective $\beta$ adrenergic function. Thus, Gerbes et a ${ }^{97}$ showed that leucocytes from patients with cirrhosis have fewer $\beta$ adrenoceptors. Moreover, studies in cirrhotic animal models indicate downregulation with reduced $\beta$ adrenergic receptor density in cardiomyocytes and receptor desensitisation. ${ }^{10}$ Recent studies have provided evidence that the cardiac dysfunction in experimental cirrhosis is in part brought about by the combination of receptor and postreceptor defects in the heart. Thus, Ma et $a l^{98}$ reported reduced function and expression of the cardiac $G$ protein in experimental cirrhosis, and Zavecz et al9 found impaired cardiac excitation contraction coupling in rats with portal hypertension. Impaired $\beta$ adrenergic signal transduction may then be an important element in the pathogenesis of cirrhotic cardiomyopathy.

Recent reports have emphasised the importance of a vagal impairment. Dillon et a $l^{100}$ reported that captopril corrected the autonomic dysfunction, which suggests that vagal dysfunction in cirrhosis is partly caused by neuromodulation by angiotensin II. Cardiac muscarinic receptors may counterbalance the positive inotropic and chronotropic effects of $\beta$ adrenergic stimulation. Recently, Jaue et $a l^{101}$ reported a blunted muscarinic response in cirrhotic rat hearts. This response was not caused by downregulation of muscarinic receptors, which suggests a potential postreceptor defect. However, the changes in muscarinic function may be compensatory, and overactivity of the parasympathetic nervous system is not likely to be a major factor in the genesis of cirrhotic cardiomyopathy.

\section{Cardiodepressant substances}

Alcoholic heart muscle disease, or alcoholic cardiomyopathy, is a well known cause of reduced left ventricular performance in alcoholic patients with and without cirrhosis. ${ }^{102}{ }^{103}$ The 


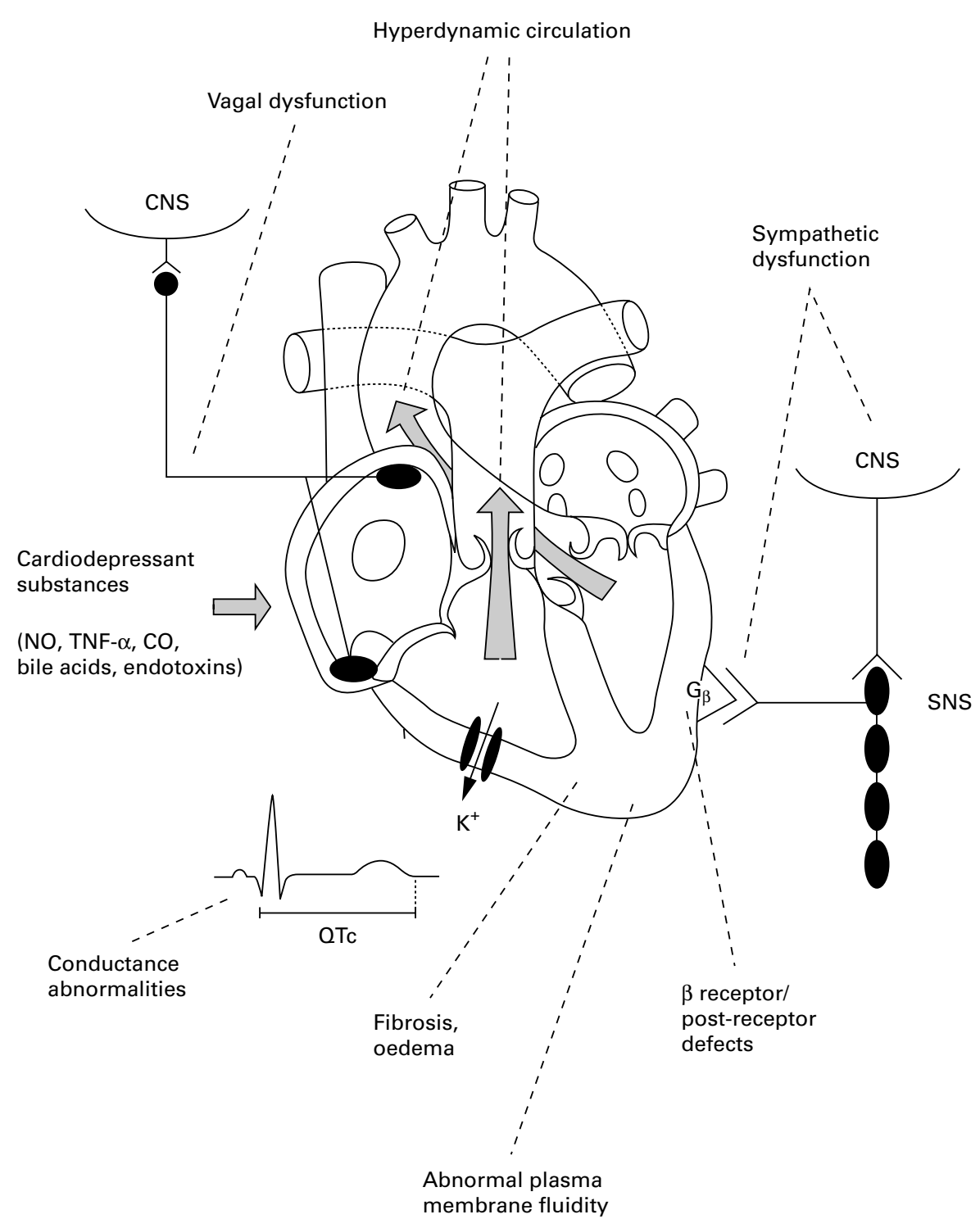

Figure 1 Potential pathophysiological components implicated in the development of cirrhotic cardiomyopathy. CNS, central nervous system; $\mathrm{CO}$, carbon monoxide; NO, nitric oxide; QT frequency adjusted QT interval; SNS sympathetic nervous system; TNF- $\alpha$, umour necrosis factor $\alpha$. distinction between alcoholic and cirrhotic cardiomyopathy can be difficult ${ }^{59}{ }^{60}$ but the pathogenesis of alcoholic and cirrhotic cardiomyopathy seems to be dissimilar. Thus, in alcoholic heart muscle disease, left ventricular performance is reduced, owing to impaired contractile protein synthesis and formation of immunogenic cardiac protein acetaldehyde adducts. ${ }^{104}$ The presence of antibodies to these adducts may be a marker for the diagnosis of this type of heart disease or possibly for its pathogenesis. The major features in cirrhotic cardiomyopathy are impaired $\beta$ adrenergic receptor function, plasma membrane dysfunction, and increased $\mathrm{CO}$.

Other potential mechanisms of impaired cardiac function in cirrhosis are production of other cardiodepressant substances, such as endotoxins, endothelins, cytokines, and bile acids. ${ }^{105}{ }^{106}$ Nitric oxide may also play a part in cardiac contractility. In an animal model, Van Obbergh et al ${ }^{107}$ observed that decreased left ventricular pressure increased after blockade of nitric oxide synthesis, which indicates that cardiac depression may be associated with nitric oxide. In a recent study on the effects of L-arginine infusion in patients with cirrhosis, left ventricular pressures were not measured, but RAP, PAP, and PCWP were all significantly increased ${ }^{44}$ Haem oxygenase is an enzyme responsible for haem degradation into carbon monoxide, iron, and biliverdin. Carbon monoxide is a potent vasodilator and this compound may also be involved in vascu- lar hyporeactivity and defective myocardial contractility in cirrhosis. ${ }^{108}$ Liu et al ${ }^{109}$ reported increased cardiac cytokinestumour necrosis factor $\alpha$ and interleukin $\mathrm{lb}$-in bile duct ligated rats. Patients with decompensated cirrhosis have increased concentrations of interleukin 6 , interleukin 8 , and tumour necrosis factor $\alpha$, which indicate that proinflammatory signals are involved in the pathogenesis of compensated and especially decompensated cirrhosis. ${ }^{110}$ As in cirrhosis, patients with congestive heart failure and dilated cardiomyopathy have an activated sympathetic nervous system and increased circulating cytokines. ${ }^{111}$ Recently, treatment with $\beta$ blockers has been shown to decrease the plasma concentration of interleukin 6 and tumour necrosis factor $\alpha$ in patients with dilated cardiomyopathy. ${ }^{112}{ }^{113} \beta$ blockers may then-in addition to their neuroendocrine effects-have an important immunoregulatory role. ${ }^{111}$ However, no such studies have yet been performed in patients with cirrhosis and whether such effects can be achieved in cirrhotic patients must be answered by future research. New anticytokine treatments are being developed to inhibit neuroendocrine and cytokine activation in chronic heart failure, and these treatments may also be relevant in the potential treatment of cirrhotic cardiomyopathy. ${ }^{111}{ }^{114}$ Cytokine stimulated activation of cardiac nitric oxide synthase in cirrhotic animal models adds further support to the involvement of the nitric oxide system in 
cirrhotic cardiomyopathy and should stimulate studies on nitric oxide inhibition. ${ }^{109}$

In patients with jaundice without cirrhosis, heart function may also be impaired. The reason is not clear but increased concentrations of bile salts have been shown to inhibit cardiac contractility. ${ }^{115} \mathrm{Ma}$ et $a l^{116}$ recently showed that cardiac function was decreased in experimental cirrhosis with various degrees of jaundice. The mechanism in this model seems to be the blockade of adenyl cyclase.

There is now basic and clinical evidence that cirrhotic cardiomyopathy differs from alcoholic cardiomyopathy, now termed alcoholic heart muscle disease, and that cirrhotic cardiomyopathy occurs frequently in non-alcoholic cirrhotic patients. In addition, toxic substances that accumulate because of impaired hepatic function may further inhibit cardiac function in these patients. Potential new treatments such as anticytokines have potential relevance.

\section{CONCLUSIONS}

Heart diseases can affect the liver with development of, for instance, cardiac cirrhosis and liver diseases may affect the heart with development of cirrhotic cardiomyopathy. Cardiac and liver diseases may also have a common aetiology, as is seen in metabolic and infectious diseases. ${ }^{117}$ From a functional point of view, the heart in cirrhosis is at the same time hyperdynamic and dysfunctional. Experimental and clinical studies of patients with cirrhosis strongly suggest the presence of latent heart failure with impaired reactions to standardised provocations. This has given rise to the introduction of the clinical entity cirrhotic cardiomyopathy, which may cover different pathophysiological mechanisms. Cirrhotic cardiomyopathy is clinically and pathophysiologically different from alcoholic heart muscle disease. Cirrhotic cardiomyopathy comprises changes in impaired cardiac contractility during the preload and afterload, decreased $\beta$ adrenergic receptor function, postreceptor dysfunction, defective excitation contraction coupling, and in some patients conductance abnormalities (fig 1). Clinically significant cardiac dysfunction and latent heart failure are the outcome. A pertinent issue for forthcoming studies is whether cirrhotic cardiomyopathy affects mortality. At present no specific treatment can be recommended and evident ventricular failure in patients with cirrhotic cardiomyopathy should be treated as non-cirrhotic causes with sodium restriction, diuretics, and afterload reduction. Cardiac glycosides may not be expected to be of significant value in cirrhotic cardiomyopathy as these failed to improve cardiac contractility after angiotensin infusion. ${ }^{38}$ Special caution should be taken during and after stressful procedures such as surgery, shunt implantation, and liver transplantation. Effects of $\beta$ blockers on cardiac function, QT interval prolongation, and mortality are subjects for future research. Newer treatments with anticytokines may also prove to be of interest in patients with cirrhotic cardiomyopathy.

\section{Authors' affiliations}

S Møller, J H Henriksen, Department of Clinical Physiology, 239, Hvidovre Hospital, University of Copenhagen, DK-2650 Hvidovre, Denmark

\section{REFERENCES}

1 Kowalski HJ, Abelmann WH. The cardiac output at rest in Laennecs cirrhosis. J Clin Invest 1953;32:1025-33.

2 Llach J, Ginés P, Arroyo V, et al. Prognostic value of arterial pressure, endogenous vasoactive systems, and renal function in cirrhotic patients admitted to the hospital for the treatment of ascites. Gastroenterology $1988 ; 94: 482-7$

3 Møller S, Wiinberg N, Henriksen JH. Noninvasive 24-hour ambulatory arterial blood pressure monitoring in cirrhosis. Hepatology 1995;22:88-95.

4 Møller S, Henriksen JH. Circulatory abnormalities in cirrhosis with focus on neurohumoral aspects. Semin Nephrol 1997; 17:505-19.
5 Henriksen JH, Møller S, Ring-Larsen $\mathrm{H}$, et al. The sympathetic nervous system in liver disease. J Hepatol 1998;29:328-41.

6 Levy M, Maher E, Wexler M. Euvolemic cirrhotic dogs in sodium balance maintain normal systemic hemodynamics. Can J Physiol Pharmacol 1988;66:80-3.

7 Fernandez-Rodriguez CM, Prieto J, Zozaya JM, et al. Arteriovenous shunting, hemodynamic changes, and renal sodium retention in liver cirrhosis. Gastroenterology 1993; 104:1139-45.

8 Epstein SK, Ciubotaru RL, Zilberberg MD, et al. Analysis of impaired exercise capacity in patients with cirrhosis. Dig Dis Sci 1998:43:1701-7.

9 Fallon MB, Abrams GA. Pulmonary dysfunction in chronic liver disease. Hepatology 2000;32:859-65

$10 \mathrm{Ma} \mathrm{Z}$, Lee SS. Cirrhotic cardiomyopathy: getting to the heart of the matter. Hepatology 1996;24:451-9.

11 Ahmed SS, Howard M, ten Hove W, et al. Cardiac function in alcoholics with cirrhosis: absence of overt cardiomyopathy: myth or fact? J Am Coll Cardiol 1984;3:696-702.

12 Møller S, Søndergaard L, Møgelvang J, et al. Decreased right heart blood volume determined by magnetic resonance imaging: evidence of central underfilling in cirrhosis. Hepatology 1995;22:472-8.

13 Friedman HS, Fernando $\mathrm{H}$. Ascites as a marker for the hyperdynamic heart of Laennec's cirrhosis. Alcohol Clin Exp Res 1992;16:968-70.

14 Wong F, Liu P, Lilly L, et al. Role of cardiac structural and functional abnormalities in the pathogenesis of hyperdynamic circulation and renal sodium retention in cirrhosis. Clin Sci 1999:97:259-67.

15 Perello A, Inserte J, Godoy A, et al. Cardiac structure and function in experimental intra-hepatic portal hypertension. [abstract] J Hepatol 2000;32:65

16 Wong F, Liu P, Tobe S, et al. Central blood volume in cirrhosis: measurement with radionuclide angiography. Hepatology $1994: 19: 312-21$

17 Rector WG Jr, Hossack KF. Pathogenesis of sodium retention complicating cirrhosis: is there room for diminished "effective" arterial blood volume? Gastroenterology 1988;95:1658-63.

18 Dancy $M$, Bland JM, Leech $G$, et al. Preclinical left ventricular abnormalities in alcoholics are independent of nutritional status, cirrhosis and cigarette smoking. Lancet 1985;i:1122-5

19 Kelbæk H, Eriksen J, Brynjolf I, et al. Cardiac performance in patients with asymptomatic alcoholic cirrhosis of the liver. Am J Cardiol 1984;54:852-5.

20 Rector WG, Robertson AD, Lewis FW, et al. Arterial underfilling does not cause sodium retention in cirrhosis. Am J Med 1993;95:286-95.

21 Rector WG Jr, Adair O, Hossack KF, et al. Atrial volume in cirrhosis: relatioship to blood volume and plasma concentrations of atrial natriuretic factor. Gastroenterology 1990;99:766-70.

22 Shah A, Variyam E. Pericardial effusion and left ventricular dysfunction associated with ascites secondary to hepatic cirrhosis. Arch Intern Med $1988 ; 148: 585-8$

23 Keller H, Bezjak V, Stegaru B, et al. Ventricular function in cirrhosis and portasystemic shunt: a two-dimensional echocardiographic study. Hepatology 1988;8:658-62

24 Estruch R, Fernandez-Sola J, Sacanella E, et al. Relationship between cardiomyopathy and liver disease in chronic alcoholism. Hepatology 1995;22:532-8.

25 Laffi G, Barletta G, Lavilla G, et al. Altered cardiovascular responsiveness to active tilting in nonalcoholic cirrhosis. Gastroenterology 1997; 113:891-8.

26 Pozzi M, Carugo S, Boari G, et al. Evidence of functional and structural cardiac abnormalities in cirrhotic patients with and without ascites. Hepatology 1997;26:1131-7.

27 Valeriano V, Funaro S, Lionetti R, et al. Modification of cardiac function in cirrhotic patients with and without ascites. Am J Gastroenterol 2000;95:3200-5

28 Henriksen JH, Bendtsen F, Sørensen TIA, et al. Reduced central blood volume in cirrhosis. Gastroenterology 1989:97:1506-13.

29 Lewis FW, Adair O, Rector WG. Arterial vasodilation is not the cause of increased cardiac output in cirrhosis. Gastroenterology 1992; 102:1024-9.

30 Meng HC, Lin HC, Tsai YT, et al. Relationships between the severity of cirrhosis and haemodynamic values in patients with cirrhosis. J Gastroenterol Hepatol 1994;9: 148-53.

31 Gould L, Shariff M, Zahir M. Cardiac hemodynamics in alcoholic patients with chronic liver disease and a presystolic gallop. J Clin Invest 1969;48:860-4

32 Gadano A, Hadengue A, Widmann JJ, et al. Hemodynamics after orthotopic liver transplantation: study of associated factors and long-term effects. Hepatology 1995;22:458-65.

33 Ruiz del Arbol L, Monescillo A, Jimenez W, et al. Paracentesis-induced circulatory dysfunction: mechanism and effect on hepatic hemodynamics in cirrhosis. Gastroenterology 1997:113:579-86.

34 Kelbæk H, Rabøl A, Brynjolf I, et al. Haemodynamic response to exercise in patients with alcoholic liver cirrhosis. Clin Physiol 1987;7:35-41

35 Friedman HS, Cirillo N, Schiano F, et al. Vasodilatory state of decompensated cirrhosis: relation to hepatic dysfunction, ascites, and vasoactive substances. Alcohol Clin Exp Res 1995;19:123-9.

36 Henriksen JH, Møller S, Schifter S, et al. Increased arterial compliance in decompensated cirrhosis. J Hepatol 1999;31:712-8.

37 Henriksen JH, Fuglsang S, Bendtsen F, et al. Arterial compliance in patients with cirrhosis. High stroke volume/pulse pressure ratio as an index of elevated arterial compliance. Am J Physiol 2001;280:G594. 
38 Limas CJ, Guiha NH, Lekagul O. Impaired left ventricular function in alcoholic cirrhosis with ascites. J Lab Clin Med 1977;89:1 175-87.

39 Vachiery F, Moreau R, Gadano A, et al. Hemodynamic and metabolic effects of terlipressin in patients with cirrhosis receiving a nonselective beta- blocker. Dig Dis Sci 1996:41:1722-6.

40 McCormick PA, Chin J, Greenslade L, et al. Cardiovascular effects of octreotide in patients with hepatic cirrhosis. Hepatology 1995;21:1255-60.

41 Escorsell A, Bandi JC, Moitinho E, et al. Time profile of the haemodynamic effects of terlipressin in portal hypertension. J Hepatol 1997; 26:621-7.

42 Elizalde JI, Moitinho E, Garcia-Pagan JC, et al. Effects of increasing blood hemoglobin levels on systemic hemodynamics of acutely anemic cirrhotic patients. J Hepatol 1998;29:789-95

43 Forrest EH, Bouchier IAD, Hayes PC. Acute effect of low dose theophylline on the circulatory disturbances of cirrhosis. Gut 1997:40:139-44

44 Kakumitsu S, Shijo H, Yokoyama $M$, et al. Effects of L-arginine on the systemic, mesenteric, and hepatic circulation in patients with cirrhosis. Hepatology 1998;27:377-82.

45 Rössle M, Ochs A, Gülberg V, et al. A comparison of paracentesis and transjugular intrahepatic portosystemic shunting in patients with ascites. N Engl J Med 2000;342:1701-7.

46 Azoulay D, Castaing D, Dennison A, et al. Transjugular intrahepatic portosystemic shunt worsens the hyperdynamic circulatory state of the cirrhotic patien: preliminary report of a prospective study. Hepatology 1994; 19:129-32.

47 Vander-Linden $\mathbf{P}$, Lemoine $O$, Ghysels $M$, et al. Pulmonary hypertension after transjugular intrahepatic portosystemic shunt: effects on right ventricular function. Hepatology 1996;23:982-7.

48 Huonker $M$, Schumacher YO, Ochs A, et al. Cardiac function and haemodynamics in alcoholic cirrhosis and effects of the transjugular intrahepatic portosystemic stent shunt. Gut 1999;44:743-8

49 Lebrec D, Givily N, Hadengue A, et al. Transjugular intrahepatic portosystemic shunts: comparison with paracentesis in patients with cirrhosis and refractory ascites: a randomized trial. J Hepatol 1996;25:135-44.

50 Lotterer E, Wengert A, Fleig WE. Transjugular intrahepatic portosystemic shunt: short-term and long-term effects on hepatic and systemic hemodynamics in patients with cirrhosis. Hepatology 1999;29:632-9.

51 Epstein M. Peritoneovenous shunt in the management of ascites and the hepatorenal syndrome. In: Epstein $M$, ed. The kidney in liver disease. Philadelphia: Hanley and Belfus, 1996:491-506

52 Moller S, Henriksen JH. Circulatory abnormalities in cirrhosis with focus on neurohumoral aspects. Semin Nephrol 1997;17:505-19.

53 Henriksen JH, Møller S, Bendtsen F, et al. Assessment of central blood volume in cirrhosis by radionuclide angiography. What does it really mean? Hepatology 1994;20:1652-3.

54 Mrller S, Bendtsen F, Henriksen JH. Effect of volume expansion on systemic hemodynamics and central and arterial blood volume in cirrhosis. Gastroenterology 1995;109:1917-25.

55 Bernardi M, Matco CD, Trevisani F, et al. The hemodynamic status of preascitic cirrhosis: an evaluation under steady-state conditions and afte postural change. Hepatology 1992;16:341-6.

56 Bernardi M, Fornale L, Dimarco C, et al. Hyperdynamic circulation of advanced cirrhosis: a re-appraisal based on posture-induced changes in hemodynamics. J Hepatol 1995;22:309-18.

57 Gentilini P, Romanelli RG, Laffi $G$, et al. Cardiovascular and renal function in normotensive and hypertensive patients with compensated cirrhosis: effects of posture. J Hepatol 1999;30:632-8

58 Epstein $M$. Renal sodium handling in liver disease. In: Epstein $M$, ed. The kidney in liver disease. Philadelphia: Hanley and Belfus, 1996:1-31.

59 Grose RD, Nolan J, Dillon JF, et al. Exercise-induced left ventricular dysfunction in alcoholic and non-alcoholic cirrhosis. J Hepatol 1995;22:326-32.

60 Bernardi M, Rubboli A, Trevisani F, et al. Reduced cardiovascular responsiveness to exercise-induced sympathoadrenergic stimulation in patients with cirrhosis. J Hepatol 1991;12:207-16.

61 Navasa M. Feu F, Garcia-Pagan JC, et al. Hemodynamic and humoral changes after liver transplantation in patients with cirrhosis. Hepatology 1993;17:355-60.

62 Piscaglia F, Zironi G, Gaiani S, et al. Systemic and splanchnic hemodynamic changes after liver transplantation for cirrhosis: a long-term prospective study. Hepatology 1999;30:58-64.

63 Myers RP, Lee SS. Cirrhotic cardiomyopathy and liver transplantation. Liver Transp/ 2000;6(4 suppl 1):S44-52.

64 Donovan CL, Marcovitz PA, Punch JD, et al. Two-dimensional and dobutamine stress echocardiography in the preoperative assessment of patients with end-stage liver disease prior to orthotopic live transplantation. Transplantation 1996:61:1180-8.

65 Ingles AC, Hernandez I, Garcia-Estan J, et al. Limited cardiac preload reserve in conscious cirrhotic rats. Am J Physiol 1991;260:H1912-7.

66 Finucci G, Desideri A, Sacerdoti D, et al. Left ventricular diastolic function in liver cirrhosis. Scand J Gastroenterol 1996;31:279-84.

67 Beyer N, Aadahl M, Strange B, et al. Improved physical performance after orthotopic liver transplantation. Liver Transp/ Surg 1999;5:301-9.

68 Liu HQ, Lee SS. Cardiopulmonary dysfunction in cirrhosis. J Gastroenterol Hepatol 1999; 14:600-8

69 Moreau R, Komaichi H, Kirstetter $\mathrm{P}$, et al. Altered control of vascular tone by adenosine triphosphate-sensitive potassium channels in rats with cirrhosis. Gastroenterology 1994;106:1016-23.
70 Moreau R, Lebrec D. Endogenous factors involved in the control of arterial tone in cirrhosis. J Hepatol 1995;22:370-6.

71 Ward CA, Ma Z, Lee SS, et al. Potassium currents in atrial and ventricular myocytes from a rat model of cirrhosis. Am J Physiol 1997;273:G537-44.

72 Day PC, James FWO, Butler JT, et al. Q-T prolongation and sudden cardiac death in patients with alcoholic liver disease lancet 1993:341:1423-8.

73 Bernardi M, Calandra S, Colantoni A, et al. Q-T interval prolongation in cirrhosis: prevalence, relationship with severity, and etiology of the disease and possible pathogenetic factors. Hepatology 1998;27:28-34

74 Mohamed R, Forsey PR, Davies MK, et al. Effect of liver transplantation on QT interval prolongation and autonomic dysfunction in end-stage liver disease. Hepatology 1996;23: 1 128-34

75 Moller S. Systemic haemodynamics in cirrhosis and portal hypertension with focus on vasoactive substances and prognosis. Dan Med Bull 1998;45: 1-14

76 Opie LH. The heart: physiology, from cell to circulation, 3rd edn. Philadelphia: Lippincott, 1998.

77 MacGilchrist AJ, Reid JL. Impairment of autonomic reflexes in cirrhosis. Am J Gastroenterol 1990;85:288-92.

78 Hendrickse MT, Triger DR. Vagal dysfunction and impaired urinary sodium and water excretion in cirrhosis. Am J Gastroenterol 1994:89:750-7.

79 Trevisani F, Sica G, Mainqua P, et al. Autonomic dysfunction and hyperdynamic circulation in cirrhosis with ascites. Hepatology 1999;30:1387-92

80 MacGilchrist AJ, Sumner D, Reid JL. Impaired pressor reactivity in cirrhosis: evidence for a peripheral vascular defect. Hepatology 1991;13:689-94.

81 Chaudhry V, Corse AM, O'Brian R, et al. Autonomic and peripheral (sensorimotor) neuropathy in chronic liver disease: a clinical and electrophysiologic study. Hepatology 1999;29:1698-703.

82 Møller S, Henriksen JH. The systemic circulation in cirrhosis. In: Arroyo $V$, Gines P, Rodes J, et al, eds. Ascites and renal dysfunction in liver disease. Malden: Blackwell, 1999:307-29.

83 Lewis FW, Cohen JA, Rector WG. Autonomic dysfunction in alcoholic cirrhosis: relationship to indicators of sympathetic activation and the occurrence of renal sodium retention. Am J Gastroenterol 1991;86:553-9.

84 Laffi G, Lagi A, Cipriani M, et al. Impaired cardiovascular autonomic response to passive tilting in cirrhosis with ascites. Hepatology 1996;24:1063-7.

85 Iwao T, Toyonaga A, Ikegami M, et al. Reduced portosystemic hemodynamic responsiveness after orthostasis in patients with cirrhosis. Dig Dis Sci 1993;38:1251-8.

86 Saijyo T, Nomura M, Nakaya Y, et al. Autonomic nervous system activity during infusion of L-arginine in patients with liver cirrhosis. Liver $1998 ; 18: 27-31$

87 Bernardi $M$, Trevisani F, Santini $C$, et al. Plasma norepinephrine, weak neurotransmitters, and renin activity during active tilting in liver cirrhosis: relationship with cardiovascular homeostasis and renal function. Hepatology 1983;3:56-64.

88 Oliver MI, Miralles R, Rubiesprat J, et al. Autonomic dysfunction in patients with non-alcoholic chronic liver disease. J Hepatol 1997;26:1242-8

89 Moreau R, Hadengue A, Soupison T, et al. Abnormal pressor response to vasopressin in patients with cirrhosis: evidence for impaired buffering mechanisms. Hepatology 1990;12:7-12.

90 Ryan J, Sudhir K, Jennings G, et al. Impaired reactivity of the peripheral vasculature to pressor agents in alcoholic cirrhosis. Gastroenterology 1993; 105:1 167-72.

91 Møller S, Hansen EF, Becker U, et al. Central and systemic haemodynamic effects of terlipressin in portal hypertensive patients. Liver 2000;20:51-9

92 Pateron D, Beyne P, Laperche T, et al. Elevated circulating cardiac troponin I in patients with cirrhosis. Hepatology 1999;29:640-3.

93 Polio J, Sieber CC, Lerner E, et al. Cardiovascular hyporesponsiveness to norepinephrine, propranolol and nitroglycerin in portal-hypertensive and aged rats. Hepatology 1993;18:128-36.

94 Castro A, Jimenez W, Claria J, et al. Impaired responsiveness to angiotensin-II in experimental cirrhosis: role of nitric oxide. Hepatology 1993; 18:367-72

95 Bomzon A. Impaired responsiveness to angiotensin II in experimental cirrhosis. Hepatology 1994;20:266-7.

96 Wu ZY, Benoit JN. Vascular NE responsiveness in portal hypertension: role of portal pressure and portosystemic shunting. Am J Physiol 1994;266:H1 162-8

97 Gerbes AL, Remien J, Jüngst D, et al. Evidence for down-regulation of beta-2-adrenoceptors in cirrhotic patients with severe ascites. Lancet 1986:i:1409-1 1

$98 \mathrm{Ma} \mathrm{Z}$, Miyamoto A, Lee SS. Role of altered beta-adrenoceptor signa transduction in the pathogenesis of cirrhotic cardiomyopathy in rats. Gastroenterology 1996;110:1191-8.

99 Zavecz JH, Bueno O, Maloney RE, et al. Cardiac excitation-contraction coupling in the portal hypertensive rat. Am J Physiol Gastrointest Liver Physiol 2000;279:G28-39.

100 Dillon JF, Nolan J, Thomas $\mathrm{H}$, et al. The correction of autonomic dysfunction in cirrhosis by captopril. J Hepatol 1997;26:331-5.

101 Jaue DN, Ma ZH, Lee SS. Cardiac muscarinic receptor function in rats with cirrhotic cardiomyopathy. Hepatology 1997:25:1361-5.

102 Kelbæk H, Nielsen BM, Eriksen J, et al. Left ventricular performance in alcoholic patients without chronic liver disease. Br Heart $J$ 1987; 58:352-7. 
103 Fernandez-Sola J, Estruch R, Grau JM, et al. The relation of alcoholic myopathy to cardiomyopathy. Ann Intern Med 1994;120 529-36.

104 Harcombe AA, Ramsay L, Kenna JG, et al. Circulating antibodies to cardiac protein-acetaldehyde adducts in alcoholic heart muscle disease. Clin Sci (Lond) 1995:88:263-8.

105 Tevelthuis H, Jansen PGM, Oudemans-Vanstraaten HM, et al. Circulating endothelin in cardiac operations: influence of blood pressure and endotoxin. Ann Thorac Surg 1996;61:904-8.

106 Chu CJ, Lee FY, Wang SS, et al. Hyperdynamic circulation of cirrhotic rats with ascites: role of endotoxin, fumour necrosis factor-alpha and nitric oxide. Clin Sci 1997;93:219-25.

107 Van Obbergh L, Vallieres Y, Blaise G. Cardiac modifications occurring in the ascitic rat with biliary cirrhosis are nitric oxide related. $J$ Hepatol 1996;24:747-52.

108 Moreau R. Heme oxygenase: protective enzyme or portal hypertensive molecule. J Hepatol 2001;34:936-9.

109 Liu H, Ma Z, Lee SS. Contribution of nitric oxide to the pathogenesis of cirrhotic cardiomyopathy in bile duct-ligated rats. Gastroenterology 2000;118:937-44.

110 Daniluk J, Szuster-Ciesielska A, Drabko J, et al. Serum cytokine levels in alcohol-related liver cirrhosis. Alcohol 2001;23:29-34
111 Niebauer J. Inflammatory mediators in heart failure. Int J Cardiol 2000;72:209-13.

112 Mabuchi N, Tsutamoto T, Kinoshita M. Therapeutic use of dopamine and beta-blockers modulates plasma interleukin-6 levels in patients with congestive heart failure. J Cardiovasc Pharmacol 2000;36(suppl 2): S87-91.

113 Ohtsuka T, Hamada M, Hiasa G, et al. Effect of beta-blockers on circulating levels of inflammatory and anti-inflammatory cytokines in patients with dilated cardiomyopathy. J Am Coll Cardiol $2001 ; 37: 412-7$.

114 Deswal A, Misra A, Bozkurt B. The role of anti-cytokine therapy in the failing heart. Heart Fail Rev $2001 ; 6: 143-51$.

115 Green J, Better OS. Systemic hypotension and renal failure in obstructive jaundice: mechanistic and therapeutic aspects. J Am Soc Nephrol 1995;5: 1853-71.

116 Ma ZH, Zhang YK, Huet PM, et al. Differential effects of jaundice and cirrhosis on beta-adrenoceptor signaling in three rat models of cirrhotic cardiomyopathy. J Hepatol 1999;30:485-91.

117 Naschitz JE, Slobodin G, Lewis RJ, et al. Heart diseases affecting the liver and liver diseases affecting the heart. Am Heart J 2000;140: $111-20$.

\section{IMAGES IN CARDIOLOGY}

\section{Ablation of haemodynamically unstable right ventricular oufflow tract ventricular tachycardia guided by non-contact mapping}

\begin{abstract}
60 year old man presented with recurrent near syncope preceded by fast palpitation for six months. Investigations showed normal left and right ventricles. Programmed electrical stimulation (PES) was able to induce clinical arrhythmia of cycle length $250 \mathrm{~ms}$ with left bundle branch block pattern and inferior axis, suggesting right ventricular outflow tract (RVOT) ventricular tachycardia (VT). Blood pressure dropped to $60 / 40 \mathrm{~mm}$ Hg during tachycardia with notable dizziness. Overdrive pacing was successful in terminating the arrhythmia. The clinical arrhythmia was not under satisfactory control by antiarrhythmic treatment and he agreed to have ablative therapy. The non-contact Ensite catheter (Endocardial Solution Inc) was positioned in the RVOT via the left femoral vein with guide wire lined up from RVOT to pulmonary artery across pulmonary valve $(\mathrm{PV})$. The geometry of the RVOT was established during sinus rhythm with location of PV, His bundle, right ventricular apex, and tricuspid annulus. VT was induced again by PES with concurrent non-contact activation mapping. VT was rapidly terminated by overdrive pacing because of low blood pressure.
\end{abstract}

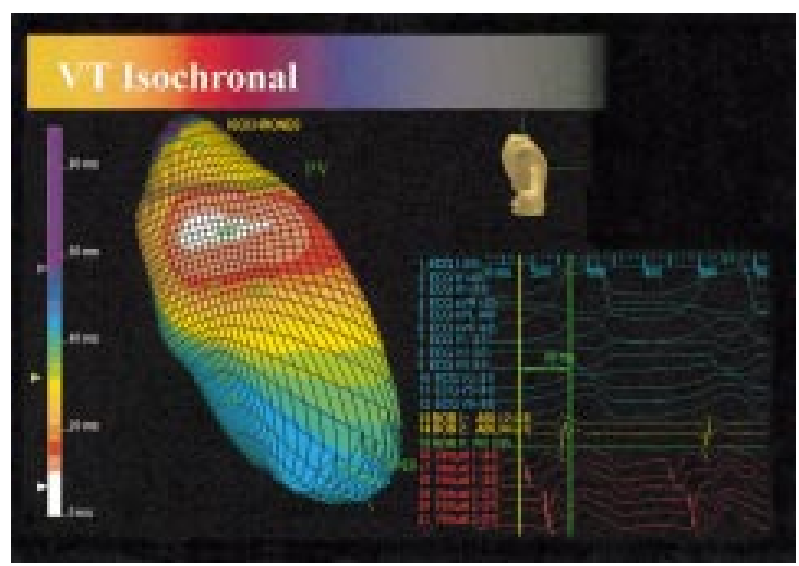

Isochronal map of patient during right ventricular tract (RVOT) ventricular tachycardia in lateral projection. White denotes the area of earliest activation $(0 \mathrm{~ms})$; red denotes the area depolarised $20 \mathrm{~ms}$ later than the white area; green and blue denote the areas depolarised 40 and $60 \mathrm{~ms}$ later than the white area.
Activation mapping information during the brief period of VT was recorded. The earliest focus of activation during VT was located at the lateral wall of RVOT below PV and propagation of depolarisation wavefront was displayed in a colour coded format with white colour denoting the earliest site ( $0 \mathrm{~ms}$ ) (below left). With the Ensite navigational guide, two radiofrequency energy applications were delivered by the roving catheter to the target focus ("white patch") during sinus rhythm. The earliest activation site of RVOT during sinus rhythm after radiofrequency ablation was at His bundle (below right). The procedure was successful and there was no recurrence without any antiarrhythmic treatment. This case illustrates that non-contact mapping can greatly facilitate ablative therapy for haemodynamically unstable arrhythmia.

\section{J W H Fung}

H C K Chan

J E Sanderson

jesanderson@cuhk.edu.hk

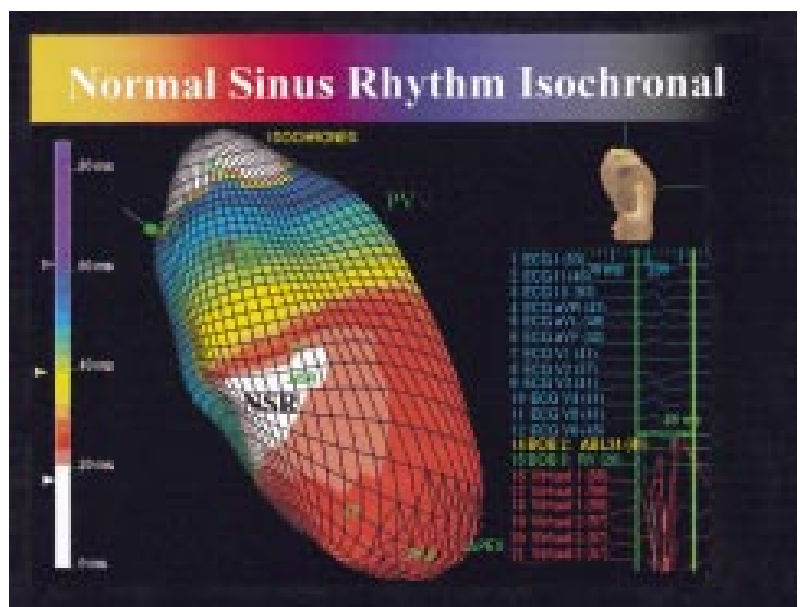

Isochronal map of patient during sinus rhythm after successful ablation in lateral projection. The two dark patches just below the pulmonary valve (PV) represent the radiofrequency ablation lesions (L). The colour coded format is identical to that of other figure. During sinus rhythm, earliest activation of RVOT was at the level of the His bundle denoted as NSR (white colour) in the map. 